\title{
Rethinking academic freedom
}

\author{
Francesca Minerva* \\ Department of Philosophy and Moral Sciences, University of Ghent, Blandijnberg 2, 9000 Ghent, Belgium
}

\begin{abstract}
The new media offer a valuable tool to spread the results of academic research outside the boundaries of academia, but they can also have a chilling effect on academic freedom. In this paper, I argue that we need to rethink academic freedom in the light of the enormous changes in communication and dissemination of ideas provided by the new media. I also argue that we need to develop strategies that would help us best use the potential of the Internet, while limiting as much as possible its potential threats to academic freedom.
\end{abstract}

KEY WORDS: Academic freedom $\cdot$ New media $\cdot$ Internet $\cdot$ Academic ethics

If writing this book has persuaded me of any one thing, it is that no single person will ever be capable of solving the problem it addresses.

(Conrad Russell, introduction to the book Academic Freedom, 1991)

\section{ARE WE ACADEMICALLY FREE?}

Like perhaps most people who started their academic career in secular countries and in secular institutions in quite recent times, I took academic freedom for granted. Unlike academics who lived and worked in previous centuries, I did not fear interference from religious or political authorities. No church or king ever imposed their teachings or research agenda on me and I (perhaps quite naively) assumed that I was allowed and, indeed even encouraged, to develop my ideas, write them in my papers and, to an extent, discuss them in teaching my students. Of course, I knew that some scholars were considered controversial and that on some occasions there had been negative or even aggressive reactions to their publications and talks, together with attempts to silence them. For instance, I knew there had been protests against the decision to hire Peter Singer at Princeton University in 1999, but the fact that he was

*Corresponding author: Francesca.Minerva@UGent.be hired despite such protests made me feel even more confident that academic freedom was safe. In 2012, certain events made me realize that I was wrong.

\section{WHAT IS ACADEMIC FREEDOM?}

According to the UK Education Reform Act 1988, Section 202 (2), academic freedom is 'the freedom [academics have] within the law to question and test received wisdom and to put forward new ideas and controversial or unpopular opinions without placing themselves in jeopardy of losing their jobs or privileges they may have at their institutions'.

Fritz Machlup similarly stated that '[a]cademic freedom consists in the absence of, or protection from, such restraints or pressures (...) as are designed to create in minds of academic scholars (...) fears and anxieties that may inhibit them from freely studying and investigating whatever they are interested in, and from freely discussing, teaching or publishing whatever opinions they have reached' (Machlup 1955, p. 753). The training involved in becoming able and entitled to write in academic journals and to be entitled to academic freedom is a long one, and a quite tough selection is involved in the process. Although the selection process is not always fair and al-

( ) The author 2016. Open Access under Creative Commons by Attribution Licence. Use, distribution and reproduction are unrestricted. Authors and original publication must be credited. 
though it ought to be improved, it is the best one we have at the moment and the only one we can rely on.

In this paper, I argue that we need to rethink academic freedom in the light of the enormous changes in the communication and dissemination of ideas brought by new media tools in a context where some groups are using it to prevent academic discussion. I will use 2 recent examples to discuss the issue of academic freedom at times when the Internet and the new media play a key role in spreading both academic ideas and ideas of academics. One case comes from my own experience, in particular from the publication in the Journal of Medical Ethics of a paper entitled 'After-birth abortion. Why should the baby live?' (Giubilini \& Minerva 2013); the other one is the case of Steven Salaita, whose job offer at the University of Illinois at Urbana Champaign was not confirmed after he posted on Twitter some comments against Israel (it is not clear yet whether, technically, he was fired or 'de-hired', but for the purpose of this paper, this difference is not relevant).

\section{THE 'AFTER-BIRTH ABORTION' PAPER CASE}

In February 2012, a paper I co-authored with Alberto Giubilini entitled 'After-birth abortion: Why should the baby live?' (Giubilini \& Minerva 2013a) appeared online first in the Journal of Medical Ethics (JME), one of the leading journals in medical ethics and one with the highest impact factor. The paper followed the train of thought explored by Michael Tooley, Peter Singer and Helga Kuhse, Jeff McMahan, Jonathan Glover, John Harris and others before us, and discussed the moral status of embryos, foetuses and newborns. The philosophical core of our arguments were not entirely new (although, of course, we did add some original elements to the philosophical discussion on infanticide, as explained below); even the title of our paper clearly suggested that we were elaborating on the arguments proposed by Singer \& Kuhse in their book Should the baby live?. The problem of handicapped infants

Unlike Singer \& Kuhse, we did not focus on handicapped newborns but on newborns in general. Our argument could be briefly summarized as following: If killing foetuses may be considered morally permissible because (we think that) they don't possess personhood in a morally relevant sense, then killing newborns should be considered morally permissible on the same grounds, and because such an argument in the case of foetuses is sometimes used to justify abortion even when the foetus is healthy, consistency demands that the same argument be used in the case of healthy newborns.

One could disagree with our premises that these 2 categories of individuals lack personhood and maintain, instead, that both foetuses and newborns possess personhood, i.e. are persons in a morally relevant sense. Alternatively, one could disagree with the premises that it is morally permissible to kill human beings who are not persons. However, the aim of our argument was to point out a potential inconsistency between the different moral beliefs (regarding foetuses and regarding newborns) of most people who are in favour of abortion.

Again, and I repeat this point because it is crucial and it has been misunderstood, even though we clarified this in several publications (Giubilini \& Minerva 2012, 2013b,c), we did not discuss the difference between handicapped and non-handicapped individuals. Nevertheless, many people misunderstood the paper and took it to be a moral defence of killing, or even an invitation to kill, disabled children. Before we could realize what was going on, we found ourselves in the eye of a media storm, which was caused in part by the fact that the arguments proposed in our paper had not always been accurately reproduced by newspapers, blogs, radio and television programmes.

The reaction of the public was extremely violent, and in the 3 years after the publication of this paper we have received, and keep receiving, hundreds of emails and messages which sound extremely aggressive and offensive, or even threatening. Articles on our papers published in online newspapers and personal websites received thousands of (usually not supportive, to say the least) comments, and this trend has not stopped since. For example, someone recently wrote to me in an email: 'if i could, i ll (sic!) spend hours mutilating $u$, heartless bitch'.

Although I obviously do not enjoy receiving such messages, and the situation has been very stressful, my main preoccupation has always been the reaction of fellow academics, not least because at the time of the publication of the paper I was, and I still am, a post-doctoral fellow and I feared that my future in academia was going to be negatively affected by these events.

My fears, unfortunately, turned out to be founded. Soon after the publication of this paper, an offer made to my co-author for a job in a prestigious ethics committee in Australia was rescinded, even though the contract had been sent and was about to be signed, and the first meeting of the committee with him as a new member had already been scheduled. Similarly, an offer for a permanent job in a philoso- 
phy department was not made to me only because, as written in the email from a member of the interview panel, some members of the department were strongly opposed to the views expressed in the paper and for this reason opposed to hiring me.

In these 2 cases, the correlation between the loss of a job opportunity and the publication of the paper was made explicit by people in the hiring committee, although it was not very wise of them to reveal the reasons behind their decision, as we could have started legal actions against them. We will never know how many job applications have been sabotaged by people who oppose our views. I suspect there may be more than one case; a blog post by an anonymous scholar ${ }^{1}$ sharing the story of how her department decided not to hire a person because of a controversial publication on (after-birth?) abortion seems to support this concern. The post stated that someone in the department had raised the issue of academic freedom, and the answer was: 'let her practice her academic freedom somewhere else'.

One could point out that, nonetheless, my academic freedom was not infringed, as I was not fired and I was lucky enough to receive substantial support from my institution, the University of Melbourne. But consistent with the definitions of academic freedom I provided above, such freedom does not consist of just not being fired (or de-hired), it also amounts to not being hindered and sabotaged in job hunting and in being supported by the academic community in the attempt to continue working on (supposedly) controversial topics.

It would be an exaggeration to claim that the reason why I do not currently hold a tenure position is exclusively because I co-authored one of the most controversial (and cited) papers in bioethics of the last few years. Nonetheless, it would also be very naive to think that that paper had no negative impact on my career and on my future jobs prospects. Apart from the aforementioned cases, I would never be able to prove that I had been denied a certain academic job because of a clash of values between those of some people on the job committee and those expressed in my paper and not because I was not the best applicant or because my research interests did not match the needs of a certain department. However, I believe I am correct in suspecting that my publication negatively affected my chances of getting a job in more than on the few occasions it was

1 https://beingawomaninphilosophy.wordpress.com/2014/11 /18/harmony/ made explicit to me. I think this because in some episodes hostility was not just directed to our ideas, but to our persons: some fellow academics refused to shake hands with me when we were introduced at a conference; others said publicly that Giubilini and I should have been banned from universities and should go speak at 'the fish market'.

I am definitely not a fainthearted person, but, since the publication of that paper I have not been able to approach my research, or other academics, without feeling uncomfortable. It is not easy to feel free to explore all the topics one believes to be important when under the impression that other people, and especially colleagues, are looking at you with suspicion. I am aware that we have no control on how other people will react to our papers and to our ideas and that not much can be done about this, but it is nonetheless important to point out that this state of things has a chilling effect on academic freedom. Perhaps if people were more aware of this phenomenon, they would think twice before doing anything that could cause their colleagues to feel uncomfortable and ostracized.

It would be misleading to say that the media are responsible for threats to academic freedom, as there were many cases of violations of academic freedom well before the Internet was invented. Academic freedom has always been very fragile, and academics have always struggled to protect themselves from external influences. In this sense, the problem of the violation of academic freedom is not necessarily related to the Internet. As a matter of fact, the new media can be used in ways that enhance academic freedom instead of threatening it. However, the media are currently used to limit academic freedom in ways that were not available 20 years ago, for example: (1) the Internet carries the discussion far outside the former boundaries of the academic discussion. Our interlocutors not only include other academics, but the much wider group of people who read newspaper and surf the web. The more people read your work, the more likely it is that someone will feel outraged. (2) Whereas in the past, people who disagreed with an idea had to take the time to write a comment or a response, send it via a post office to the editor of a journal or newspaper (who would select the publishable responses), or just to the author of the paper, and go through a series of procedures that might discourage them to send such comments, they can now do it while sitting on their sofa, and in just a few seconds. (3) Whatever is written on the Internet is immortal, and irrespective of whether the information about a person is later proved to be 
false or even ignominious, it will stay accessible to everyone and forever. In the past, information in the newspapers would no longer be readily accessible after a while.

In summary, the Internet and social media do not represent a threat to academic freedom per se, but they can be a powerful instrument in the hands of those who want to control academia.

\section{ON THE IMPORTANCE OF PUBLISHING CONTROVERSIAL PAPERS}

It has been stated in many venues and in many private conversations that Giubilini and I should have expected (and sometimes that we deserved) what happened to us, because we should have known that the paper we were writing would be considered controversial. Leaving aside the fact that no paper in bioethics had previously attracted so much hostility from both the public and academics and that it was therefore difficult to predict such a negative response, I still struggle to understand why one should expect to endanger their career because of a paper they publish.

The word 'controversial', especially in a field like philosophy, should have a descriptive, and not a normative value. To say that a certain scientific hypothesis or philosophical argument is controversial, simply describes the fact that such a hypothesis or argument challenges common sense or the mainstream academic view on that particular issue. However, unless our thinking is fallacious, we cannot draw any normative conclusion from the empirical fact that many ideas that challenged common sense in the past turned out to be true and/or are currently accepted.

Conrad Russell, a famous historian and son of the even more famous Bertrand Russell (who lost 2 jobs because of his ideas) in his book Academic Freedom wrote that 'it must be absolutely impermissible to silence academic research because it conflicts with received ideas. Indeed, there is perhaps a greater duty to give it serious attention if it conflicts with received ideas' (Russell 1993, p. 34). Besides, it is not just common sense, but what is considered academic 'mainstream' ideas, that could conflict with new theories, hypotheses and arguments. While it is true that academics need to 'stand on the shoulders of giants', we should not rely too much on these giants. If a scientist is able to provide empirical evidence to support their hypotheses, and their paper passes a scrupulous peer review, then their results should be published even though the empirical evidence we had before seemed to support a different hypothesis. Philosophy is a theoretical discipline, and consensus is not necessarily reached on the basis of empirical evidence. However, we philosophers test the coherence, the rationality or the reasonability of a view.

A paper can provoke strong reactions, even disgust and revulsion; nonetheless, philosophers need to scrupulously test the reasonableness and the soundness of each other's arguments, and by necessity such scrupulous analysis involves the rationalization of views: philosophical arguments have to be coherent and rational. It is one thing to say that an argument is unsound and quite another to say that its conclusions are repugnant. Thus, we should not make the mistake of claiming that an argument is unsound just because we find its conclusions to be repugnant.

In a response to the after-birth abortion paper, Matthew Beard and Sandra Lynch wrote that when Peter Singer and Helga Kuhse published Should the baby live?, philosopher Raimond Gaita pointed to the conclusion of their arguments as evidence of the invalidity of their views (Beard \& Lynch 2013). According to Gaita, a conclusion that contradicts the basic moral intuition that a newborn should be protected is sufficient evidence to dismiss the argument. If Gaita were correct, humans would never change their deeply held beliefs or make any moral progress. The idea that slaves were people like everyone else must have sounded quite counterintuitive in ancient Greece, to mention just one example. About 30 years after the publication of Singer \& Kuhse's book, Gaita wrote: 'If Singer's arguments for infanticide are now accepted as deserving of serious consideration, it is not just because of their logical force. It is because changes in the culture have disposed us to accept a conclusion that only thirty years ago discredited any arguments that led to it' (Gaita 2004, p. 100-101). I find this passage very interesting for the purpose of this paper because, although perhaps unintentionally, Gaita highlights the importance of discussing arguments that seem to be (to some, or to the majority) easily discreditable or disgusting. Those changes in the culture Gaita talks about did not happen by chance, but also (or even mainly) because they were prompted by philosophical discussion.

As the prominent bioethicist Udo Schüklenk wrote, '[a]cademics have always challenged assumptions taken for granted by the mainstream. That is how progress is possible. Some of the challenges succeed and lead to societal change, some fail after significant societal controversy, the majority probably sink without a trace altogether' (Schüklenk 2013, p. 305). What 
matters the most, I believe, is that we meet these challenges and do not shy away from questions we think ought to be answered.

\section{STEVEN SALAITA'S TWITTER CASE}

So far I have discussed what can happen to academic papers and their authors when something written for a public of specialists is discussed in the media arena; sometimes the boundary between 'public discussion' and 'cyber bullying' can be very porous, especially when people, and not their arguments, are under the magnifying glass of inquiry. I have also argued that media uproar can have a chilling effect on academic freedom by instilling in academics fears of violent reactions on the part of the public and of negative reactions from fellow academics. In this section, I will instead focus on what can happen to academics when they share their ideas directly in the media arena and on social networks. In order to discuss this point, I will present a case that has been much debated in the last few months, the case of Steven Salaita.

Steven Salaita is a Professor of American Indian Studies, who in October 2013 signed a job contract with the University of Illinois at Urbana-Champaign (UIUC) and resigned from his previous position at Virginia Tech. At the beginning of August 2014, after the Board of Trustees noticed some of Salaita's comments posted on Twitter, UIUC Chancellor told Salaita they were not going to approve his hiring.

The core of the contention, and it is crucial to stress this point, were not comments made in the classroom, nor in academic work but tweets such as the following ones:

'You may be too refined to say it, but I'm not: I wish all the fucking West Bank settlers would go missing.'

[Jeffrey Goldberg's] 'story should have ended at the pointy end of a shiv.'

'If you're defending Israel right now, you are an awful human being.'

'Zionists: transforming 'antisemitism' from something horrible into something honorable since 1948' and 'Zionist uplift in America: Every little Jewish boy and girl in America can grow up to be the leader of a murderous colonial regime.'

There are various ways to interpret these tweets, some more charitable than others with respect to what Salaita meant. Regardless of which interpretation one might embrace, I suspect we can all agree that such sentences (also because of the way they are formulated) would not have been published in a peer-reviewed article or in any other academic venue. These tweets could not be mistaken for excerpts of academic work, and they were meant to express Salaita's personal views on the policies of Israel rather than to develop arguments. In the words of Gerard Dworkin, the tweets 'are expressed in a way that I find disgusting, vicious, and disrespectful'르. Generally, I do not think people, whether academics or not, should express themselves in such a fashion. But what Dworkin and I might find disgusting is irrelevant to the matter we are discussing. So, despite the fact that I did not like those tweets, I think that Salaita should not have been fired (or de-hired), and that the fact that those tweets sounded 'disgusting' or 'disrespectful' says nothing about his value as an academic and about his capacity to publish in academic journals and to be a good teacher.

One question that is crucial in relation to Salaita's case and academic freedom at the time of the Internet is whether Tweets, Facebook posts, Blog posts, etc. are protected by academic freedom.

\section{ON THE DIFFERENCE BETWEEN ACADEMIC FREEDOM AND FREEDOM OF THE ACADEMIC}

Cary Nelson, a Professor at UIUC, former president of the American Association of University Professors (AAUP) and a current member of the AAUP's Committee A on Academic Freedom and Tenure, defended the decisions to fire or de-hire Salaita. When asked whether this decision could be presented as the decision to punish a scholar for his unpopular political views, Nelson answered that he did not think this was the case because '[i]f Salaita had limited himself to expressing his hostility to Israel in academic publications subjected to peer review, I believe the appointment would have gone through without difficulty'르․

Thus, according to Nelson, the fact that Salaita's ideas had not been shared through the traditional channels of academic communication made all the difference. Had Salaita written the same, identical sentences in a peer-reviewed article or in an academic book, he would not have been fired (or dehired) because whatever he would have written in an academic publication would have been protected by

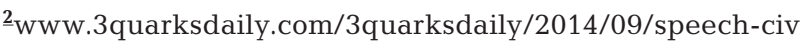
ility-and-the-salaita-case.html (last accessed 05/02/2015). ${ }^{3}$ www.insidehighered.com/news/2014/08/06/u-illi-noisapparently-revokes-job-offer-controversial-scholar (last accessed 10/02/2015).
} 
academic freedom. This point is quite important for the purpose of this paper, because it seems to draw a clear distinction between academic freedom and freedom of academics. In the case of the after-birth abortion paper, I suppose that Nelson would argue that, given that the paper was published in a peerreviewed journal, the authors were protected by academic freedom.

This interpretation of academic freedom is more focused on the academic status of the publication, rather than on the fact that the person in question is an academic. This means that, no matter how controversial an argument may be, if it passes the peer review, then it can have a place in the academic debate, and the person who developed such an argument cannot be fired or punished in any way. However, one of the problems with this view is that the difference between academic and non-academic publications can sometimes be blurred. Some scientific journals, for instance, accept brief comments and letters to the editors which are not peer reviewed. It is usually agreed that such comments, although non peer reviewed, have an academic status and could/should be considered as protected by academic freedom. Many research centers and departments have their own blogs, and academics post on them non peer-reviewed short articles which clearly have a different status compared to the personal blog the same academics may use to share pictures of their family and of their last meal.

Thus, the approach according to which only academic publications should be considered protected by academic freedom runs into the problem of defining exactly what constitutes an academic publication, and this is becoming an increasingly difficult task.

\section{FREEDOM OF ACADEMICS}

A quite different interpretation of the relationship between academic freedom and the media is presented in a document developed by Committee A on Academic Freedom and Tenure selected by AAUP in 2004 and revised in $2013^{4}$. In the report it is stated that 'each institution [should] work with its faculty to develop policies governing the use of social media. Any such policy must recognize that social media can be used to make extramural utterances and thus their use is subject to Association-supported principles of academic freedom, which encompass extramural

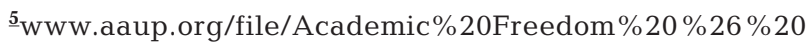
Electronic\%20Communications.pdf
}

utterances' (AAUP 2013, p. 51) and 'Professors should also have the freedom to address the larger community with regard to any matter of social, political, economic, or other interest, without institutional discipline or restraint, save in response to fundamental violations of professional ethics or statements that suggest disciplinary incompetence' (AAUP 2013, p. 52). In other words, according to this AAUP report, academics should be protected by academic freedom (within some broad limits) regardless of whether they publish their ideas in academic venues or on social media. In particular, the AAUP committee considers the large public reached through social media to be an extended classroom that academics ought to involve in the debate about all sorts of topics without having to fear about their jobs.

According to the AAUP report, Salaita was protected by academic freedom also when he was 'tweeting' his thoughts on Israel's policies. Indeed, the AAUP published a 'Statement on Case of Steven Salaita' in which they defend the right of Salaita 'to express their views without fear of retaliation, even where such views are expressed in a manner that others might find offensive or repugnant ${ }^{\prime}$. In the same statement it is also mentioned 'that faculty comments made on social media, including Twitter, are largely extramural statements of personal views that should be protected by academic freedom'. In this sense, academic freedom collapses into the broader concept of freedom of speech, as no distinction is made between personal views on a topic and views developed as an expert in the field. Hence, academic freedom entails the right of academics to spread both their academic and non-academic views in both academic and non-academic venues. This approach, too, has pros and cons.

One positive aspect of this approach is that it allows academics to share their ideas outside of the classroom and scientific publications, bringing the findings and the ideas of academics outside that ivory tower where they have been confined for centuries. Moreover, this approach seems to be more in line with the current understanding of the role of an academic: anyone who has ever applied for a grant knows very well that one of the requirements for obtaining funding for research is to prove to have the intention and the capacity to spread the outcomes of the research among the public, well beyond the narrow boundaries of academia. If these are the current demands made on aca-

\footnotetext{
$\underline{5}_{\text {www.aaup.org/media-release/statement-case-steven- }}$ salaita
} 
demics, it would seem unfair, on one hand, to strongly encourage them to use social media and the Internet to reach the public and, on the other hand, have them constantly worry that their use and possible misuse of these media will cause them to be fired, de-hired or ostracized by the academic community. However, there are also problems with this approach, as explained in the following section.

\section{WHO IS AN EXPERT?}

When we publish in specialized journals, our level of competence is tested by the referees and the editor. The fact that a paper is accepted for publication in a good, peer-reviewed journal proves that a certain academic's views on a certain topic are the result of their studies and these views are accepted by other experts in the field (or at least, this is the hope). However, tweets, blog posts and articles for the lay public are not peer reviewed. There is no certificate that guarantees that what an academic is claiming is trustworthy, as the published content has not been approved by a committee of experts (the peer reviewers). In general, this is not a problem, since academics usually write blog posts and newspapers articles on topics on which they are knowledgeable, and they usually simplify the content of their academic research in order to make it accessible to a group of non-specialists.

However, things could go wrong. For example, I am passionate about nutrition and I like reading on this topic, but I do not have a PhD in the subject and cannot be considered an expert on nutrition issues. Therefore, if I start tweeting claims about nutritionsaying, for instance that a high fat diet is healthier than a high sugar diet-I am not really contributing to the academic discussion on the topic, I am not communicating my expertise to the public, and I am not speaking as an expert. However, since nobody has control over what is written on the social media fares, there is some chance that my tweets on nutrition could be mistaken for tweets of an expert in the field.

We may underestimate how contents that are published in online public forums can be easily misunderstood. For instance, in the online articles that talked about 'Dr. Francesca Minerva' following the publication of the after-birth abortion paper, many people mistakenly assumed that I am a medical doctor and not a Doctor of Philosophy. In some cases, they wrote me very angry emails saying that my duty, as a doctor, was to heal patients, and not to kill them. This episode made me realize that people can become very confused about the real nature of our areas of expertise and the potential dangers of people misinterpreting some claims as true (or based on the best evidence available) rather than the hypothesis of an academic with no particular knowledge in that field. In this sense, academics may have to avoid tweeting about subjects they know little about. An alternative solution could be to always begin a tweet with the qualification 'I am no expert, but I think that ...', although this provides no guarantee that a certain sentence will not be reported in other venues without the initial disclaimer.

Although society as a whole has a lot to gain from being exposed to new ideas and findings developed in academia, there is the problem of ensuring that people outside academia distinguish between what we claim as experts and what we claim as nonexperts. This is particularly important in cases where these misunderstandings could generate very negative consequences. J. S. Mill famously said that 'an opinion that corn-dealers are starvers of the poor, or that private property is robbery, ought to be unmolested when simply circulated through the press, but may just incur punishment when delivered orally to an excited mob assembled before the house of a corn-dealer'(Mill 1869; Chapter III, paragraph I). At a time when information travels faster than any time before, and any opinion can reach far more people, it becomes very difficult to understand whether we are talking to a general public or to 'an excited mob assembled before the house of a corn-dealer'. Moreover, as academics, we need to be particularly careful because our opinions, if received as 'experts' opinions', could have more weight, and hence more serious consequences, than other people's opinions.

It may be that our freedom of speech would have to be limited for the sake of our academic credibility. However, if our classroom potentially includes all of our Facebook and Twitter followers (and in a sense, whoever has access to the Internet), we may have good reasons to be careful when we post a sentence that could be interpreted as an expert's opinion and which could have negative consequences. This is true for statements about good or bad diets and, more importantly, for statements that might be received as an invitation to commit a violent act.

\section{FREEDOM FROM ACADEMIA}

I have so far discussed the freedom of academia and academics from institutional and public interferences. However, there is also a problem with limita- 
tions to academic freedom coming from academia itself. I have highlighted the importance of peer review to provide a guide as to what topics and contents should be discussed, and I think that it is very important that these boundaries are developed by academics and for academics and not from external powers. However, we academics have to be wary of our own judgments and make sure that we make an extra effort in assessing why an argument, or a thesis, or a hypothesis, or a research question is not worthy of pursuit. The need to please donors who inevitably have their own opinions, the fear of upsetting such donors because of media uproars, and the increasing independence of universities from external grants, are causing an increase in the general level of caution in academia.

Limitation of academic freedom from within academia can take 2 different forms: (1) it can be selfimposed, for example when academics decide to investigate a non controversial topic rather than a controversial one because they are worried about the possible negative consequences; and (2) it can be imposed by other academics who discourage their colleagues from investigating a certain topic or eventually ostracize them for pursuing a certain line of research. In this sense, although I have argued that peer review is a hallmark of a certain academic standard, peer review could be misused to thwart other people's research rather than ensuring that a publication meets a certain standard. In this case (and it is plausible to think that this happens sometimes) it would be quite problematic to maintain that academic freedom should protect only peer-reviewed publications. As stated at the beginning, academic freedom is supposed to protect 'the freedom within the law to question and test received wisdom and to put forward new ideas and controversial or unpopular opinions'. However, to make it impossible for such ideas to be developed and discussed is to impose a preventive censorship on ourselves or on our colleagues.

Fritz Machlup wrote that the fact that 'only 3 or 4 of every thousand professors would ever have occasion to say or write things that would bring them into conflict with the authorities, or with power groups in society, explains why it is sometimes difficult to rally all faculty members to the vigorous support of academic freedom (Machup 1955, p. 757). According to Machlup, the majority of people in academia are not interested in controversies and would resent the activities of the 'trouble makers'. However, although these 'safe players' might think they do not benefit from academic freedom as academics, they actually benefit from it both as academics and as members of society. In Machlup's words, 'It is important that the few potential trouble makers are encouraged to voice their dissent, because on such dissent, however unpopular, the advancement of our knowledge and the development of material, social, or spiritual improvements may depend (Machup 1955, p.757). Of course, this does not mean that progress only happens thanks to trouble makers, but the point is that trouble makers too have an important role in academia, and although sometimes it may seem easier to silence them, in the long-term this strategy would not pay off. On this note, I would add that I have been told that bioethicists are often very careful to avoid talking about infanticide because it is a very dangerous and controversial topic.

I think, and I believe Machlup would have agreed with me, that by avoiding controversial topics we are betraying our mission and our duty to academic freedom, because we are not testing new ideas in the pursuit of knowledge and truth. Infanticide and afterbirth abortion may be morally permissible or impermissible, but the discussion is still open, and there is no reason to avoid this topic. What should concern us is not only, or mainly, a ban on the topic of infanticide and the ostracism of people who work on such a topic, but academic freedom itself which is at stake. Our capacity to be free in the face of possible negative consequences is at stake and our intellectual honesty and credibility before society at risk, a society which includes people who send death threats to those working on disturbing topics but to whom, nevertheless, we owe our intellectual honesty. When we identify an important question we think we should try to answer but we decide to ignore it because we fear for ourselves, we are betraying the trust of society who gave us the privilege of doing such an important job, and we wrong all the people who fought for academic freedom and paid a very high price for it. We also wrong future academics, because we teach them, through our example, that being a coward pays more than being free. If this is the take home lesson, future generations of academics will probably consist of cowards who do not dare to ask themselves the questions they consider important because they are too afraid of what society or other academics will think of them.

However, the responsibility of being brave, intellectually honest, and genuinely curious should not be just on the shoulders of a single academic individual. All academics have a duty to defend academic freedom, and especially the academic freedom of people they disagree with. Of course, this does not mean 
that we have a duty to agree with whatever other academics say. For instance, I appreciated that Charles Camosy, a theologian, defended the publication of the article (and our academic freedom) even though he strongly disagreed with us (Camosy 2013).

\section{CONCLUSIONS}

I think we need to take the issue of academic freedom more seriously and start thinking of the various threats currently posed to it, not least the threat that each of us represents to both our own academic freedom and to our peers' academic freedom. Only if we come to agree that censorship should not operate as a preventive force, can we then say that we really deserve a right to academic freedom. Furthermore, only if we learn how to be free within our own scholarly community, can we withstand external threats. Academic freedom is a privilege and a duty, and it demands one to be brave and push discussions beyond the boundaries of what society finds acceptable or comfortable at any given time.

As R. Dworkin wrote, 'I claim that my own profession - the weak battalions of university teachers carries much of the responsibility for maintaining a magnificent ethical tradition, and that we must defend our freedom, with passion and whatever strength we all together have on that ground. We have lately become less confident of our importance, and less ready to insist on our independence. We have allowed academic freedom to seem pale and abstract and even fraudulent. But we must now remember how easy it has proved, elsewhere, for that freedom to be lost, and how hard it is to regain once lost. We do carry a great responsibility, and it is time we carried it once again with pride' (Dworkin 1996, p. 197).

It is undeniable that the new media represent a powerful tool to spread the results of academic research among other academics and the public. Academics sometimes lament the fact that their research does not have any impact on the real world, but the advent of the new media allows them to have much more impact and to influence current thinking and debate more than they could have before the Internet.

We have learnt that social media empower the public or third parties, allowing them to have an enormous influence on academia. The influence goes both ways: as academics, we have more impact on the world, and the world has more impact on our academic (and non-academic) lives. This is beautiful, but it is also dangerous. Interestingly, Cardinal Bagnasco, president of the Conference of the Italian Catholic Bishops since 2007 and vice-president of the Conference of European Catholic Bishops since 2011, recently referred to the concept of 'after-birth abortion' (or post-partum abortion) 3 times in 3 different public speeches. Maurizio Mori, a prominent Italian bioethicist, thinks that Bagnasco showed a shift in his approach to after-birth abortion, as he first discarded it as morally abhorrent and then, over the time, he accepted it as a topic we need to discuss (of course, he still considered it extremely immoral). To Mori, such a shift suggests that 'reflection and discussion at the academic level has the potential to shape public debates and to prompt people to reflect on important, neglected issues' (Mori 2015).

The advantages of using social media and the Internet in terms of spreading and testing ideas, influencing the world, and participating in a global debate are so enormous that it would be absurd to go back to the safer, but less efficient, way of communicating with peers and the public. However, we need to take into account the risks posed by the social media and to develop strategies to cope with them.

We need to develop rules that help us utilize the potential of the Internet at its best while limiting as much as possible its potential threats to academic freedom. Here, I present a few thoughts that I believe could be a starting point for discussion, without claiming that they are complete:

(1) When using social media, we need to remember that anything that is said on the Internet can be taken out of context, distorted and manipulated. Therefore, we need to be as clear as possible and try to write so that even the shortest tweets can stand by themselves without being too easily distorted.

(2) We need to remember that what we say has an impact on the world, and we have to be extremely careful not to say things which are misleading or could be taken to justify acts of violence or harm to or even the killing of other people. For instance, there is an open debate in academia on the topic of the moral justifiability of torture in some contexts. However, it would be unwise of people who share arguments in favour of torture in some circumstances to tweet sentences such as 'It's OK to torture people', or even 'it's OK to torture $\mathrm{X}$ and $\mathrm{Y}^{\prime}$, without any qualification and referral to the theoretical and complex framework within which this conviction has been elaborated.

(3) We have to be careful with publicly expressing opinions in social media on topics we are not expert in. As I previously argued, if I am a philosopher with an interest in nutrition, I need to be cautious when 
writing about topics related to nutrition and make it clear I am no expert. It is true that most people would understand that I am talking on topics which are not my area of expertise, and they would automatically interpret my statements on these subjects with much more scepticism than when I post something about philosophy, but on social networks these things can nonetheless generate misunderstandings. In particular, any comment that could conceivably be read as an invitation to be violent should be phrased in a very careful way.

(4) We should avoid expressing ourselves in ways which are not appropriate to academic standards. For instance, we do not think it is acceptable for a lecturer to use swearwords when talking to students or in academic papers. Likewise, when we express our ideas on academic issues on the Internet, we should abide by this standard. As stated in the Academic Freedom of Professors and Institutions report by the AAUP 'College and university teachers are citizens, members of a learned profession, and officers of an educational institution. When they speak or write as citizens, they should be free from institutional censorship or discipline, but their special position in the community imposes special obligations. As scholars and educational officers, they should remember that the public may judge their profession and their institution by their utterances. Hence, they should at all times be accurate, should exercise appropriate restraint, should show respect for the opinions of others, and should make every effort to indicate that they are not speaking for the institution' (AAUP 2002).

(5) Finally, but perhaps most importantly, we need to defend each other's academic freedom, no matter how much we disagree with the views expressed by other fellow academics. We need to protect academic freedom not just because what happened to me, Salaita, or to many others could happen to anyone, even those who think they will never be caught in a controversy, but because we have a duty to defend the highest standards of research. Research and ideas flourish when people are not chilled by the fear

Editorial responsibility: Konstantinos Stergiou, Thessaloniki, Greece of being fired or ostracized. Ultimately, a strenuous defence of academic freedom is the only means we have to prove our love for knowledge.

Acknowledgements. The author thanks Alberto Giubilini, Ole-Martin Moen and Maurizio Mori for their very useful comments on an earlier draft of this paper.

\section{LITERATURE CITED}

AAUP (2002) Academic freedom of individual professors and higher education institutions: the current legal landscape.www.Aaup.Org/Sites/Default/Files/Files/Academic $\%$ 20Freedom $\% 20$-\%20Whose \%20Right $\% 20$ (WEBSITE\%20COPY)_6-26-02

AAUP (2013) Academic freedom and electronic communications. www.aaup.org/file/Academic $\% 20$ Freedom $\% 20 \%$ $26 \% 20$ Electronic \% 20Communications.pdf

Beard M, Lynch S (2013) Personhood, harm and interest: a reply to Alberto Giubilini and Francesca Minerva. J Med Ethics 39:e1-e4

Camosy C (2013) Is the pro-choice position for infanticide 'madness'? J Med Ethics 39:301-302

Dworkin R (1996) We need a new interpretation of academic freedom. In: Menand L (ed) The future of academic freedom. University of Chicago Press, Chicago, IL, p. 187-198

Gaita R (2004) Moral inquiry at a Catholic University. In: Fisher A, Ramsay R (eds) Faith and reason: friends or foes in the new millenium? ATF Press, Adelaide, p 95-112

Giubilini A, Minerva F (2012) Defending after-birth abortion. Monash Bioeth Rev 30:49-61

Giubilini A, Minerva F (2013a) After-birth abortion: Why should the baby live? J Med Ethics 39:261-263

Giubilini A, Minerva F (2013b) Some clarification on the moral status of newborns. J Med Ethics 39:264-265

Giubilini A, Minerva F (2013c) Reasons and freedom. Hastings Cent Rep 43:4-5

Kuhse H, Singer P. (1985) Shoul d the baby live? The problem of handicapped infants. Oxford University Press, Oxford

Machlup F (1955) On some misconceptions concerning academic freedom. AAUP Bull 41:753-784

Mill JS (1869) On liberty. Longman, Roberts \& Green, London

Mori M (2015) After birth abortion: three years on. http:// jme.bmj.com/letters/\#content-block

Russell C (1993) Academic freedom. Routledge, New York, NY

Schüklenk U (2013) In defence of academic freedom: bioethics journals under siege. J Med Ethics 39:303-306

Submitted: February 24, 2015; Accepted: October 20, 2015

Proofs received from author(s): December 2, 2015 